\title{
Annelerin Doğum Sonrası Depresif Duygusal Bozukluklar Açısından Değerlendirilmesi ve Emzirme Üzerine Etkilerinin Belirlenmesi
}

\author{
Evaluation of Maternal Postpartum Depressive Emotional Disorders and \\ Determination of Their Effects on Breastfeeding
}

\section{Sara EROL ${ }^{1}$, Nilgün ALTUNTAŞ ${ }^{1}$}

1. Yıldırım Beyazıt Üniv., Tıp Fakültesi, Çocuk Sağlı̆̆ı ve Hastalıkları Ana Bilim Dalı, Neonatoloji Bilim Dalı, Ankara, Türkiye

\section{$\ddot{O Z Z T T}$}

Amaç: Doğum sonrası süreçte annelerde gözlenen depresif duygu-durum değişiklikleri anne, bebek ve toplum sağllğ l bakımından önemlidir. Postpartum depresyon için gelistirilen tarama testlerinin klinik kullanımları hastalı̆̆ın önlenmesi, hasta bireylerin erken tanınması ve tedavi edilmesinin sağlanmast için önerilmektedir. Bu çalışma ile annelerde postpartum depresif duygusal bozukluklar üzerine etki eden risk faktörlerini ve depresif duygusal bozuklukların emzirme üzerine etkilerini değerlendirmek amaçlanmaktadır.

Gereçler ve Yöntem: Çalışmaya Nisan 2018- Ekim 2018 tarihleri arasında hastanemizde doğum yapan ve çalıșmaya katılmayı kabul eden anneler ve bebekleri dâhil edildi. Bu çalışma için yerel etik komiteden onay alındi. Çalıșmaya katılan annelerin yaşlarl, gebelik ve doğum sayıları, doğum şekilleri, maddi durumlarl, eğitim düzeyleri, eş destekleri, bebeklerinin cinsiyetleri, doğum ağırlıkları ve gestasyon haftalar, bebeklerin başvuru sırasındaki vücut ağırlıkları, beslenme şekilleri ve hastane yatışlarının olup olmadığ kaydedildi. Tüm annelere EPDS testi ile postpartum depresyon taramast yapıld.

Bulgular: Çalışmaya 100 anne- bebek çifti katıld. Annelerin yaşları median 29 (19-39) ve çallşmada spontan vajinal doğum oranı \% 48 idi. Bebeklerin oğum ă̆ırlıkları median $3300 \mathrm{gr}(1700 \mathrm{gr}-4500 \mathrm{gr})$, gestasyon haftalarl median 38 hafta ( 34 hafta-41 hafta) idi. EPDS skorunun 10'un üzerinde olması ile anne yaşının büyük olmast, anne sütüne ek olarak mama verilmesi, gebelikte kayı öyküsünün olması ve bebeğin hastanede yatışııın olması arasında istatistiksel olarak anlaml pozitif ilişki saptandl. EPDS skoru 10'un altında olan 58 annenin 48'inin $(\% 82,7)$ bebeklerini sadece anne sütü ile beslediği, EPDS puanı 10 ve üzerinde olan 42 annenin 27 sinin $(\% 64,2)$ bebeklerini sadece anne sütü ile beslediği saptandl. Bu fark istatistiksel olarak anlamlı bulundu $(p=0,035)$.

Sonuç: Postpartum depresyon açısından risk taşıyan bireylerin önceden belirlenmesi, bu anneler için psikososyal desteğin daha erken ve güçlü verilmesi bakımından önemlidir. Postpartum depresyon gelişimin önlenmesi bebeklerin anne sütü ile beslenme oranlarını artıracaktır.

Anahtar Kelimeler: postpartum depresyon, anne sütü, edinburgh

\section{ABSTRACT}

Objective: Maternal depressive changes in postpartum period are important for mother, infant and community health. The clinical use of screening tests developed for postpartum depression is recommended for prevention of disease, early diagnosis and treatment of patients.

\section{Iletişim:}

Sorumlu Yazar: Sara EROL

Adres: Yıldırım Beyazıt Üniversitesi, Tıp Fakültesi, Çocuk Sağlığı ve Hast. Ana Bilim Dalı, Neonatoloji Bilim Dalı, Ankara, Türkiye Tel: +90 (312) 9061000

E-Posta: sarasurmeli@gmail.com

Makale Geliş: 14.12.2018

Makale Kabul: 18.02.2019

DOI: http://dx.doi.org/10.16948/zktipb.527120
The aims of this study are to evaluate the effective risk factors on postpartum depressive emotional disorders in mothers and to evaluate the effects of depressive emotional disorders on breastfeeding.

Material and Methods: Between April 2018 and October 2018, mothers who gave birth in our hospital and who agreed to participate in the study and their babies were included. Approval was obtained from the local ethics committee for this study. Age of mothers, numbers of pregnancies and births, forms of birth, financial conditions, education levels, partner supports, genders of infants, birth weights and gestational weeks, the body weight of infants at the time of application, feeding patterns and whether or not hospitalizations were recorded. All mothers were screened for postpartum depression by EPDS test.

Results: 100 mother-infant couples participated in the study. Median ages of mothers was 29 (19-39) and spontaneous vaginal birth rate was $48 \%$. The median weight of the infants was $3300 \mathrm{~g}(1700 \mathrm{~g}-4500 \mathrm{~g})$ and gestational weeks were median 38 weeks (34 weeks - 41 weeks). There was a statistically significant positive correlation between the EPDS score of more than 10 and maternal age, feeding of breast milk, the history of loss of pregnancy and the hospitalization of the baby. It was found that 48 (82.7\%) of 58 mothers with EPDS score less than 10 had only breast milk and 27 (64.2\%) of 42 mothers with EPDS score of 10 or higher fed their babies only with breast milk. This difference was statistically significant $(p=0.035)$.

Conclusion: The prediction of individuals at risk for postpartum depression is important for providing early and strong psychosocial support to these mothers. Prevention of postpartum depression will increase the feeding rate of infants with breast milk.

Keywords: postpartum depression, breast milk, edinburgh

\section{GíRIS}

Postpartum depresyon, doğum sonrası süreçte annede görülen depresif ataklar ile karakterize ciddi bir klinik tablodur (1). Farklı çalışmalarda sıklığı değişmekle birlikte doğum sonrası kadınların tahminen \%13-19'unu etkilemektedir (2). Doğum sonrasında çoğu kadında irritabilite, anksiyete, uyku problemleri, değişken ruh hali, ağlama atakları gibi geçici duygusal değişiklikler gözlenmektedir. $\mathrm{Bu}$ duygusal değişiklikler 10 gün içerisinde çoğu kadinda kaybolurken, postpartum depresyonlu annelerde üzüntü, karamsarlık ve umutsuzluk gibi depresif duygu-durum değişiklikleri ilerleyen günlerde de devam etmektedir (3).

Postpartum depresyon için çok sayıda risk faktörü tanımlanmıştır. Annede psikiyatrik hastalık öyküsü, yetersiz eș desteği, bağımlılık yapıcı madde kullanımı ve istismara maruz kalmak postpartum 
depresyon riskini artıran faktörler arasındadır (4). Bunlara ek olarak adolesan anneler, düşük sosyoekonomik düzeyi olanlar, göçmenler ve babalar da postpartum depresyon için riskli grup içerisinde yer almaktadir (5).

Postpartum depresyonlu kadınların yaklaşık \% 30'unda bu durum 2 yildan uzun süre devam etmektedir (6). Obsesif-kompulsif bozukluk, anksiyete bozuklukları, kendine ve bebeğine zarar verme eğilimi ve intihar düşünceleri postpartum depresyonlu annelerde daha sik görülmektedir (7). Postpartum depresyon kadın sağlığı kadar, çocuk ve toplum sağlığı açısından da oldukça önemli bir sorundur. Postpartum depresyonlu annelerin bebeklerinin sosyal, duygusal, fiziksel ve bilişsel gelişim açıcından uzun dönemde negatif etkilendikleri bilinmektedir (8). $\mathrm{Bu}$ nedenlerle birinci basamak hekimleri ve kadın doğum hekimleri tarafindan doğum öncesi vizitlerde anne adaylarının psikolojik yönden iyi değerlendirilmeleri ve riskli grupların erken belirlenmesi oldukça önemlidir. Doğum sonrasında ise anne- bebek sağlığ1 ve bağlanması açısından çocuk hekimlerinin, kadın doğum ve aile hekimlerinin vizitlerinde mutlaka annelere, postpartum depresyon tarama testi yapmaları hastalığın önlenmesi, hasta bireylerin erken tanınması ve tedavi edilmesinin sağlanması için önerilmektedir (9).

Amerikan Jinekoloji ve Obstetrik Birliği postpartum depresyon taraması için perinatal dönemde Edinburgh Postpartum Depresyon Skalası (EPDS)'nın kullanılmasını önermektedir (10). Bu çalışmanın primer amacı pediatri vizitleri sırasında yap1lan postpartum depresyon taramasi ile postpartum depresif bozukluk gelişimi üzerine etkili faktörlerin belirlenmesidir. Sekonder amaç ise annede görülen depresif duygu-durum değişikliklerinin emzirme üzerine etkisini değerlendirmektir.

\section{GEREÇ ve YÖNTEM}

Postpartum depresyon, doğum sonrası süreçte annede görülen depresif ataklar ile karakterize ciddi bir klinik tablodur (1). Farklı çalışmalarda sıklığg1 değişmekle birlikte doğum sonrası kadınların tahminen \%13-19'unu etkilemektedir (2). Doğum sonrasında çoğu kadında irritabilite, anksiyete, uyku problemleri, değișken ruh hali, ağlama atakları gibi geçici duygusal değişiklikler gözlenmektedir. Bu duygusal değişiklikler 10 gün içerisinde çoğu kadinda kaybolurken, postpartum depresyonlu annelerde üzüntü, karamsarlik ve umutsuzluk gibi depresif duygu-durum değişiklikleri ilerleyen günlerde de devam etmektedir (3).

Postpartum depresyon için çok sayıda risk faktörü tanımlanmıştır. Annede psikiyatrik hastalık öyküsü, yetersiz eş desteği, bağımlılık yapıcı madde kullanımı ve istismara maruz kalmak postpartum depresyon riskini artıran faktörler arasındadır (4). Bunlara ek olarak adolesan anneler, düşük sosyoekonomik düzeyi olanlar, göçmenler ve babalar da postpartum depresyon için riskli grup içerisinde yer almaktadır (5).
Postpartum depresyonlu kadınların yaklaşık \% 30 'unda bu durum 2 yıldan uzun süre devam etmektedir (6). Obsesif-kompulsif bozukluk, anksiyete bozuklukları, kendine ve bebeğine zarar verme eğilimi ve intihar düşünceleri postpartum depresyonlu annelerde daha sik görülmektedir (7). Postpartum depresyon kadın sağlığı kadar, çocuk ve toplum sağlığı açısından da oldukça önemli bir sorundur. Postpartum depresyonlu annelerin bebeklerinin sosyal, duygusal, fiziksel ve bilişsel gelişim açıcından uzun dönemde negatif etkilendikleri bilinmektedir (8). $\mathrm{Bu}$ nedenlerle birinci basamak hekimleri ve kadın doğum hekimleri tarafından doğum öncesi vizitlerde anne adaylarının psikolojik yönden iyi değerlendirilmeleri ve riskli grupların erken belirlenmesi oldukça önemlidir. Doğum sonrasında ise anne- bebek sağlığ1 ve bağlanması açısından çocuk hekimlerinin, kadın doğum ve aile hekimlerinin vizitlerinde mutlaka annelere, postpartum depresyon tarama testi yapmaları hastalığın önlenmesi, hasta bireylerin erken tanınması ve tedavi edilmesinin sağlanması için önerilmektedir (9).

Amerikan Jinekoloji ve Obstetrik Birliği postpartum depresyon taraması için perinatal dönemde Edinburgh Postpartum Depresyon Skalası (EPDS)'nın kullanılmasını önermektedir (10). Bu çalışmanın primer amacı pediatri vizitleri sırasında yap1lan postpartum depresyon taramasi ile postpartum depresif bozukluk gelişimi üzerine etkili faktörlerin belirlenmesidir. Sekonder amaç ise annede görülen depresif duygu-durum değişikliklerinin emzirme üzerine etkisini değerlendirmektir.

\section{BULGULAR}

Çalışmaya Nisan 2018- Ekim 2018 tarihleri arasında bebekleri için hastanemiz yenidoğan polikliniğgine başvuran ve çalışmaya katılmayı kabul eden anneler dahil edildi. Çalışma için yerel etik komiteden onay alınd.

Çalışmaya katılan annelerin yaşları, gebelik ve doğum sayıları, doğum şekilleri, maddi durumları, eğitim düzeyleri, eş destekleri, emzirme eğitimi alıp almadikları, bebeklerinin cinsiyetleri, doğum ağırlıkları ve gestasyon haftaları, bebeklerin başvuru sırasındaki vücut ağırlıkları, beslenme şekilleri ve hastane yatışlarının olup olmadığ1 kaydedildi. Tüm annelere EPDS testi ile postpartum depresyon taraması yapıldı. EPDS puanı 10 ve üzerinde olan anneler ve EPDS puanı 10'un altında olan anneler olmak üzere 2 grup oluşturuldu. Her iki grup arasında diğer değişkenler açısından fark ve ilişki olup olmadığ 1 istatistiksel olarak değerlendirildi.

Edinburgh Postpartum Depresyon Skalası skoru 10 ve üzerinde olan annelere 1 ay sonra telefonla ulaşılld1. Bu görüşmede annelere tekrar EPDS testi uyguland1. Bu testlerin skorları, annelerin ilk test sonuçları ile karşılaştırıldı.

Ístatistiksel yöntem: Verilerin istatistiksel analizinde SPSS for Windows 20 kullanıldı. Değişkenlerin dağılım formlarının belirlenmesi için Shapiro 
Wilk's testi yapıldı. Verilerin özetlenmesinde normal dağılım gösteren değişkenlerde (parametrik) ortalama $\pm \mathrm{SD}$, normal dağılım göstermeyen değişkenlerde (nonparametrik) median değerler kullanıld1. Normal dağılım gösteren değişkenlerin gruplararası karşılaştırılmalarında Independent samples $\mathrm{t}$ test (Bağımsız örneklerde $\mathrm{t}$ testi, student $\mathrm{t}$ test), normal dağılım göstermeyen değişkenlerin gruplararası karşılaştırılmalarında ise Mann Whitney $\mathrm{U}$ testi kullanıldı. Nominal değişkenlerin grupları arasındaki ilişkiler incelenirken Ki-Kare analizi uyguland1. $2 \times 2$ tablolarda gözelerdeki beklenen değerlerin yeterli hacme sahip olmaması durumlarında Fisher'sExact Test, RxC tablolarda ise Monte Carlo Simülasyonu yardımıyla Pearson Ki-Kare analizi kullanıldı. $\mathrm{p}<0.05$ istatistiksel anlamlı kabul edildi.

\section{Sonuçlar:}

Çalışmaya 100 anne- bebek çifti katıldı. Annelerin yaşları median 29 (19-39), gebelik sayıları median 2 (1-5) idi. Çalışmada spontan vajinal doğum oran $1 \% 48$ 'di. Bebeklerin 38'i k1z, 62'si erkekti. Doğum ağırlıkları median 3300 gr (1700 gr-4500 gr), gestasyon haftaları median 38 hafta (34 hafta-41 hafta) idi.

Çalışmaya katılan annelere EPDS testi median postpartum 15. (6 gün-40 gün) günde yapıldı. 42 annede skor 10 ve üzerinde bulundu. EPDS skoru 10'un altında olan annelerin yaşları median 26 (18-39) iken, EPDS skoru 10 ve üzerindeki annelerin yaşlar1 median 31 (18-39) saptand1. Bu fark istatistiksel olarak anlamlı bulundu $(\mathrm{p}=0,008)$. EPDS skoru 10 ve üzerinde olan annelerle, EPDS skoru 10'un altında olan annelerin bebeklerinin doğum ağırlıkları, cinsiyetleri, gestasyonel haftaları, kilo alım hızları, doğum şekilleri benzer bulundu. EPDS skoru 10'un altında olan 58 anneden sadece $5(\% 8,6)$ 'inin gebelikleri sırasında kayıp yaşadığı, EPDS skoru 10 ve üzerinde olan 42 anneden 10 'unun (\% 23,8) kayıp yaşadığı saptandı. Bu fark istatistiksel olarak anlamlı bulundu $(\mathrm{p}=0,037)$ (Tablo 1).

Edinburgh Postpartum Depresyon Skalas1 skoru 10'un altında olan 58 annenin 48'inin $(\% 82,7)$ bebeklerini sadece anne sütü ile beslediği, EPDS puan1 10 ve üzerinde olan 42 annenin 27'sinin $(\% 64,2)$ bebeklerini sadece anne sütü ile beslediği saptandı. $\mathrm{Bu}$ fark istatistiksel olarak anlamlı bulundu $(\mathrm{p}=$ 0,035) (Tablo1).
Sadece anne sütü ile beslenen 75 bebeğin 48 'inin (\%64) annesinin EPDS skoru 10'un altında iken, anne sütüne ek olarak mama da alan 25 bebeğin 10'unun (\%40) EPDS skorlar1 10'un altında saptand1. Bu fark istatistiksel olarak anlamliyd1 $(\mathrm{p}=$ $0,035)$.

Edinburgh Postpartum Depresyon Skalas1 skorunun 10 'un üzerinde olması ile anne yaşının büyük olmas1, anne sütüne ek olarak mama verilmesi, gebelikte kayıp öyküsünün olması ve bebeğin hastanede yatışının olması arasında istatistiksel olarak anlamlı pozitif ilişki saptandı. Partner desteğinin, annenin eğitim ve maddi durumunun, gebelik ve doğum say1sının, bebeğin cinsiyetinin, doğum ağırlığının ve doğum şeklinin EPDS skorunun 10 ve üzerinde olması ile istatistiksel olarak anlamlı ilişkisi saptanmadı.

Edinburgh Postpartum Depresyon Skalas1 skoru 10 ve üzerindeki 42 anneye bir ay sonra ikinci kez EPDS testi yapıld1. Annelerden $30(\% 71,4)$ 'unun EPDS skorlarının 10'un altında olduğu görüldü. EPDS skorlar1 10 ve üzerinde devam eden 12 annenin $(\% 52,2)$ ise 7 'sinin $(\% 30,4)$ EPDS skorunun ilk teste göre en az 2 puan düştügü ve bu 7 annenin tamamının EPDS puanlarının 13'ün altında olduğu görüldü. EPDS skoru 10 ve üzerindeki 5 annenin $(\% 21,8)$ ikinci testinde ise ilk teste göre EPDS skorlarının yükselerek 13 ve üzerinde oldukları saptandı. Hastaların ilk testlerinin skorları, ikinci testlerinin skorlarına göre istatistiksel olarak anlamlı şekilde yüksek saptand $1(\mathrm{p}=, 000)$.

\section{TARTIŞMA}

Postpartum depresyon taramalarının tanısal performansı pek çok faktöre bağlı değişkenlik göstermektedir. Yapılan testin özellikleri, referans ve cut-off değerleri, yapılma zamanı ve sıklığ 1 bunlardan sadece bir kısmıdır. Testin yapılacağı popülasyonun özellikleri de tanısal performans açısından oldukça önemlidir. Postpartum depresyonun daha sık görüldügü obez hastalarda, adölesan annelerde, göçmenlerde, 1rksal ve etnik farklılık durumlarında testin değerlerdirilmesi, bu riskleri taşımayan popülasyonlara göre farklı olmalıdır $(1,5)$.

Postpartum depresyona yönelik tarama testlerinin sensitiviteleri ve spesifiteleri farklidır (1). Bununla birlikte Amerikan Jineokoloji ve Obstetrik Birliği, perinatal depresyon açısından en az bir kere prenatal

Tablo 1: EPDS skorunun diğer değişkenlerle ilişsisi.

\begin{tabular}{|l|c|c|}
\hline & EPDS skoru $<10$ & EPDS skoru $\geq 10$ \\
& $\mathrm{~N}=58$ & N=42 değeri \\
\hline Anne yaşı (yıl) & $26(18-39)$ & $31(18-39)$ \\
\hline Doğum ağırlıkları (ortalama-gr) & $3290(1700-4035)$ & $3320(2000-4500)$ \\
\hline Cinsiyet (kız- \%) & $\% 39,7$ & 0,008 \\
\hline Doğum şekli (sezeryan-\%) & $\% 55,2$ & 0,662 \\
\hline Gestasyonel hafta (ortalama- hafta) & $38,5(35-41)$ & $38(34-41)$ \\
\hline Kilo alım hızı (ortalama -gr/gün) & $19(-70-53)$ & $15(-47-60)$ \\
\hline Gebelikte kayıp yaşama (adet-\%) & $5-\% 8,6$ & $10-\% 23,8$ \\
\hline Sadece anne sütü ile besleme (adet- $\%)$ & $48-\% 82,7$ & 0,302 \\
\hline
\end{tabular}


ya da postnatal dönemde EPDS testinin yap1lmasinı önermektedir (10). Amerikan Pediatri Akademisi de benzer şekilde pediatri vizitinin bir parçası olarak, postpartum dönemdeki annelerin depresyon açısından taranmasını önermektedir (9). Taramanın zamanı ve testlerin cut-off değerleri hakkında ise kesin öneri bulunmamaktadır. Tarama testi olarak sıklıkla kullanılan EPDS testi 1987'de geliștirilmiştir. Testin orjjinalinde majör depresyon bulguları açısından uyarıcı cut-off skoru 13 ve üzeri olarak belirtilmiştir. Ancak toplum taramalarında postpartum depresyon potansiyeli olan tüm vakaları saptamak amaciyla cut-off skorunun 10 ve üzeri olarak alınması önerilmiștir $(11,12)$. EPDS testi kullanılarak yapılan sonraki çalışmalarda ise testin yapılış zamanı ve yapıldığ 1 popülasyona göre farklı cut-off değerleri kullanılmıştır. Bu çalışmalar göstermiştir ki yanlış pozitiflikleri azaltmak için iki aşamalı bir tarama programı uygulandığında en uygun eşik 10 ve üzeridir (13). Çalışmamızda ülkemizde yapılan diğer çalışmalardan farklı olarak cut-off değeri 10 ve üzeri olarak belirlenmiş ve iki aşamalı tarama testi uygulanmıştır.

Tarama testlerinin doğru zamanlaması ile ilgili yapılan araştırmaların sonucunda postpartum ilk ayda yapilan tarama testlerinin sonraki aylarda yapilan testlere göre sensitivite ve spesivitelerinin daha düşük olduğu görülmüştür. İlk 2 haftada yapılan tarama testlerindeki yanlış pozitiflik, bu haftalarda postpartum annelerin çoğunda görülen geçici duygusal dalgalanmalara bağlı olabilir (14). Nitekim çalışmamizda ortalama 15. günde yapılan ilk EPDS testine göre, 1 ay sonra telefonla ulaşılarak yapılan EPDS testinde skorların anlamlı şekilde düştügü görülmektedir. Bununla birlikte tarama testlerini doğum sonrasında erken dönemde bir kere yapmak yavaş gelişen postpartum depresyon vakalarının atlanmasina neden olabilir (15).

Çalışmaların bir kısmında adölesan annelerin postpartum depresyon açısından risk grubu olduğu vurgulanırken (16), adölesan anne olmanın riski artırmadığı ancak anne yaşının 30'un üzerinde olmasının postpartum depresyon riskini artırdığını gösteren yayınlar da vardır (17). Bazı çalışmalarda ise maternal yaş faktörünün, önceden geçirilmiş depresyon öyküsü olan anneler için önemi vurgulanmıştır (18). Çalışmamızın sonuçları da anne yaşının depresif değişiklikler gösteren annelerde daha yüksek olduğu yönündeydi. Ancak araştırma grubumuzda adölesan dönemde ve 40 yaş üzerinde anne bulunmadığı için popülasyonu genelleyecek bir yorum yapılamamaktadır.

Kadınların önceki gebeliklerinin düşükle sonuçlanması sonraki gebelikler için psikolojik bir stres faktörüdür. 901 hamile kadın üzerinde bu konuyla ilgili yapılan geniş kapsamlı bir çalışmada düşük yapan gebelerin depresyon ve anksiyete oranlarının diğer gebelere göre daha yüksek olduğu ve bu durumun düșük yapılan gestasyon haftasından ve gebelikler arası süreden bağımsız olduğu saptanmıştır (19). Çalışmamızda da daha önceden düşük öyküsü olan kadınlarda postpartum dönemde depresif bulguların daha sık olduğu görülmektedir. Bu sonuç önceki gebeliği düşükle sonuçlanmış anneler için prenatal ve postnatal psikolojik desteğin çok daha önemli olduğunu göstermesi bakımından dikkat çekicidir.

Yenidoğan döneminde bebeği hastanede yatan annelerin stres ve anksiyete düzeyleri, sağlıklı bebeklerin annelerine göre daha yüksektir. Anne - bebek bağlanması için kritik bir dönemde bebeğinden ayrılan annenin kendiyle ilgili yetersizlik duyguları ve bebeğiyle ilgili endişeleri oldukça fazladır (20). Çalışmamızda bebeği yenidoğan döneminde hastanede yatan annelerde depresif duyguların, sağlıklı bebeklerin annelerine göre daha sik olduğu görülmektedir. Pediatri vizitlerinin de bir parçası olması gereken postpartum depresyon taraması özellikle yenidoğan yoğun bakımda yatan bebeklerin annelerine mutlaka uygulanmalı ve depresif bulgular erken tespit edilip yeterli destek sağlanmalıdır.

Emzirme ile postpartum depresyon arasındaki ilişkiyi iki yönlü olarak araştıran çok sayıda çalışma bulunmaktadır. Postpartum depresyonun düşük emzirme oranları ve emzirmenin erken kesilmesine neden olduğunu gösteren yayınların yanı sıra (21) emzirmenin postpartum depresyona karşı koruyucu olduğunu ve semptomların daha hızlı gerilediğini gösteren çalışmalar da bulunmaktadır (22). Bunların aksine emziren annelerde postpartum depresyonun daha fazla görüldügünü savunan yazarlar olmakla birlikte (23) son yıllarda yapılan araştırmaların çoğunda formula ile beslenen bebeklerin annelerinde postpartum depresyonun daha fazla olduğu ortaya konmuștur (24). Bizim çalıșmamızda depresif bulgular bulunan annelerde formula verme sikl1ğının daha fazla olduğu, bunun yanında sadece anne sütü ile beslenen bebeklerin annelerinde depresif semptomların daha az görüldüğü saptanmıştır. Emzirmenin, strese yanıt olarak gelişen nöroendokrin değişiklikleri kontrol ederek annenin duygusal durumu üzerine olumlu etkiler yaptığı ileri sürülmektedir. Ayrıca laktasyonun strese karşı oluşan kortizol yanıtını azalttığ1, oksitosin ve prolaktinin annenin duygu-durumu üzerine olumlu etkileri olduğu bilinmektedir (25). Bizim sonuçlarımızda da bebeği sadece anne sütü ile beslemenin anne açısından pozitif etkileri açıkça görülmektedir. Anne sütünün çok değerli olduğu gerçeği de göz önüne alındığında postpartum depresyonun önlenmesi hem anne sütü ile beslenme oranlarını artıracak, bu oran arttıkça da postpartum depresyon azalacaktır. Bu sonuç toplum sağlığı açısından oldukça önemlidir.

Çalışmamızın eksik yönleri, popülasyon büyüklüğünün yeterli olmamas1, adölesan ve ileri yaş annelerin çalışma grubunda yer almamasıdır. Ayrıca tarama testinin tüm annelerde tekrar edilememesi geç başlangıç gösteren depresif semptomların ortaya konamaması nedeniyle çalışmanın gücünü azaltmaktadır. Ancak tüm bunlara rağmen, farklı bir cutoff değeri kullanılarak yapılmış olması, tekrarlanan test uygulaması, sadece annelerin değil bebeklerin de beslenme şekilleri, kilo alımları gibi fiziksel gelişim süreçlerinin izlendiği bir çalışma olması bakımından sonuçlarımız önemlidir. 
Sonuç olarak önemli bir toplum sağllğ 1 problemi olan ve oldukça sık görülen postpartum depresyonun erken tanınması ve tedavi edilecek olguların erken belirlenmesi açısından perinatal dönemde tarama testleri yapılmalıdır. Bu taramalar kadın doğum, pediatri ve aile hekimlerinin sorumluluğudur. Risk içeren grupların önceden belirlenmesi ise bu anneler için psikososyal desteğin daha erken ve güçlü verilmesi bakımından önceliklidir. Bebeklerin anne sütü ile beslenmesinin sağlanabilmesi açısından da, anneye verilecek bu destekler önemlidir. Konuyla ilgili çok daha kapsamlı ve geniş katılımlı çalışmaların yapılması, ülkemizdeki postpartum depresyon sıklığının ve tarama için kullanılacak toplumumuza özgü cut-off değerlerinin belirlenmesi açısından gereklidir.

\section{KAYNAKLAR}

1. Ukatu N, Clare CA, Brulja M. Postpartum Depression Screening Tools: A Review. Psychosomatics. 2018 May;59 (3):211-19

2. O'Hara MW, McCabe JE. Postpartum depression: current status and future directions.

Annu Rev Clin Psychol. 2013;9:379-407

3. Heron J, Haque S, Oyebode F, Craddock N, Jones I. A longitudinal study of hypomania and depression symptoms in pregnancy and the postpartum period. Bipolar Disord. 2009;11 (4):410-7

4. Bobo WV, Yawn BP. Concise review for physicians and other clinicians: postpartum depression. Mayo Clin Proc. 2014;89 (6): $835-44$

5. Clare CA, Yeh J. Postpartum depression in special populations: a review. Obstet Gynecol Surv. 2012;67 (5):313-23

6. Horowitz JA, Goodman J. A longitudinal study of maternal postpartum depression symptoms. Res Theory Nurs Pract. 2004; $18(2-3): 149-63$

7. Miller ES, Hoxha D, Wisner KL, Gossett DR. The impact of perinatal depression on the evolution of anxiety and obsessive-compulsive symptoms. Arch Womens Ment Health. 2015;18 (3):457-61

8. Field T. Postpartum depression effects on early interactions, parenting, and safety practices: a review. Infant Behav Dev. 2010 ;33 (1):1-6

9. Earls MF; Committee on Psychosocial Aspects of Child and Family Health American Academy of Pediatrics. Incorporating recognition and management of perinatal and postpartum depression into pediatric practice. Pediatrics. 2010;126 (5):1032-9

10. Committee on Obstetric Practice. The American College of Obstetricians and Gynecologists Committee Opinion no. 630. Screening for perinatal depression. Obstet Gynecol. 2015 May;125 (5):1268-71

11. Cox JL, Holden JM, Sagovsky R. Detection of postnatal depression. Development of the 10-item Edinburgh Postnatal Depression Scale. Br J Psychiatry. 1987;150:782-6
12. Yawn BP, Pace W, Wollan PC, Bertram S, Kurland M, Graham D, Dietrich A. Concordance of Edinburgh Postnatal Depression Scale (EPDS) and Patient Health Questionnaire (PHQ9) to assess increased risk of depression among postpartum women. J Am Board Fam Med. 2009;22 (5):483-91

13. Usuda K, Nishi D, Okazaki E, Makino M, Sano Y. Optimal cut-off score of the Edinburgh Postnatal Depression Scale for major depressive episode during pregnancy in Japan. Psychiatry Clin Neurosci. 2017;71 (12):836-42

14. Owora AH, Carabin H, Reese J, Garwe T. Diagnostic performance of major depression disorder case-finding instruments used among mothers of young children in the United States: A systematic review. J Affect Disord. 2016;201:185-93

15. Wilkinson A, Anderson S, Wheeler SB. Screening for and Treating Postpartum Depression and Psychosis: A Cost-Effectiveness Analysis. Matern Child Health J. 2017;21 (4):903-14

16. Lanzi RG, Bert SC, Jacobs BK. Depression among a sample of first-time adolescent and adult mothers. $J$ Child Adolesc Psychiatr Nurs. 2009;22 (4):194-202.

17. Salihu HM, Luke S, Alio AP, Deutsch A, Marty PJ. The impact of obesity on spontaneous and medically indicated preterm birth among adolescent mothers. Arch Gynecol Obstet. 2010;282 (2):127-34

18. Silverman ME, Reichenberg A, Savitz DA, Cnattingius $S, L i$ chtenstein P, Hultman CM, Larsson H, Sandin S. The risk factors for postpartum depression: A population-based study. Depress Anxiety. 2017;:34 (2):178-87

19. Gravensteen IK, Jacobsen EM, Sandset PM, Helgadottir LB, Rådestad I, Sandvik L, Ekeberg. Anxiety, depression and relationship satisfaction in the pregnancy following stillbirth and after the birth of a live-born baby: a prospective study. BMC Pregnancy Childbirth. 2018;18 (1):41

20. Lefkowitz DSI, Baxt C, Evans JR. Prevalence and correlates of posttraumatic stress and postpartum depression in parents of infants in the Neonatal Intensive Care Unit (NICU). J Clin Psychol Med Settings. 2010;17 (3):230-7

21. Seimyr L1, Edhborg M, Lundh W, Sjögren B. In the shadow of maternal depressed mood: experiences of parenthood during the first year after childbirth. J Psychosom Obstet Gynaecol. $2004 ; 25$ (1):23-34

22. Figueiredo B, Canário C, Field T. Breastfeeding is negatively affected by prenatal depression and reduces postpartum depression. Psychol Med. 2014;44 (5):927-36

23. Chaudron LH, Klein MH, Remington P, Palta M, Allen C, Essex MJ. Predictors, prodromes and incidence of postpartum depression. J Psychosom Obstet Gynaecol. 2001;22 (2):10312

24. Groër MW. Differences between exclusive breastfeeders, formula-feeders, and controls: a study of stress, mood, and endocrine variables. Biol Res Nurs. 2005:7 (2):106-17

25. Stuebe AM1, Grewen K, Pedersen CA, Propper C, Meltzer-Brody S. Failed lactation and perinatal depression: common problems with shared neuroendocrine mechanisms? J Womens Health (Larchmt). 2012;21 (3):264-72. 